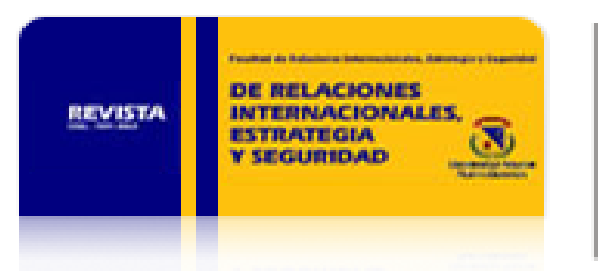

Revista de Relaciones Internacionales, Estrategia y Seguridad

ISSN: 1909-3063

cinuv.relinternal@unimilitar.edu.co

Universidad Militar Nueva Granada

Colombia

Sandoval, Carlos Germán

GOBIERNOS ELECTRÓNICOS Y ACCIÓN COLECTIVA A TRAVÉS DEL INTERNET: DINÁMICAS

EN LA REGIÓN ANDINA

Revista de Relaciones Internacionales, Estrategia y Seguridad, vol. 4, núm. 1, enero-junio, 2009, pp. 31-53

Universidad Militar Nueva Granada

Bogotá, Colombia

Disponible en: http://www.redalyc.org/articulo.oa?id=92712970003

- Cómo citar el artículo

Número completo

- Más información del artículo

- Página de la revista en redalyc.org

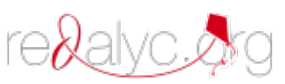

Sistema de Información Científica

Red de Revistas Científicas de América Latina, el Caribe, España y Portugal

Proyecto académico sin fines de lucro, desarrollado bajo la iniciativa de acceso abierto 
rev.relac.int.estrateg.segur.4(1):31-53,2009

\title{
GOBIERNOS ELECTRÓNICOS Y ACCIÓN COLECTIVA A TRAVÉS DEL INTERNET: DINÁMICAS EN LA REGIÓN ANDINA*
}

\author{
Carlos Germán Sandoval ${ }^{* *}$
}

\section{RESUMEN}

Este artículo realiza una aproximación a los vínculos entre las nuevas tecnologías informáticas, el Estado y los movimientos sociales, en el marco de la región andina y desde una perspectiva de análisis político. A partir de una reconstrucción de los procesos que dieron origen a las Agendas de Conectividad, se analiza la dinámica de adopción de los gobiernos electrónicos y la dinámica de copamiento del internet por parte de los movimientos sociales. Se recogen estas experiencias teóricas y prácticas para reflexionar en torno al comportamiento del Estado y

\footnotetext{
*El presente texto hace parte de los resultados de las investigaciones «Debates sobre conectividad: retos y prioridades» (2008), y «Gobierno en Línea en Colombia» (2009), apoyadas por la Universidad Nacional de Colombia.

**Politólogo, candidato a Magister en Análisis de problemas políticos, económicos y relaciones internacionales del Instituto de Altos Estudios para el Desarrollo. Investigador y asistente editorial del Instituto de Estudios Políticos y Relaciones Internacionales (IEPRI) de la Universidad Nacional de Colombia. cgsandovalf@unal.edu.co
} 
de los movimientos sociales en su encuentro con el mundo informático y la llamada era digital. El artículo plantea que cada una de estas dinámicas configura trayectorias y objetivos diferentes frente a la construcción del Estado, la democracia y la ciudadanía.

Palabras clave: internet, conectividad, gobiernos electrónicos, acción colectiva, movimientos sociales, región andina.

\section{ABSTRACT}

This article approaches the links between new information technologies, the state and new social movements within the Andean region and from a perspective of political analysis. Starting from a reconstruction of the processes that originated connectivity agendas, the dynamics behind the adoption of electronic governance and internet filling up by social movements is analyzed. These theoretic and practical experiences are gathered to aid reflection about the state and the social movement's behavior in their encounters with the info world and the so called digital era. The article maintains that each of these dynamics configures different trajectories and objectives facing the construction of democracy and citizenship.

Key words: Internet, connectivity, electronic governance, collective action, social movements, Andean region.

\section{INTRODUCCIÓN}

A escaso tiempo de conmemorarse el Bicentenario de Independencia en los países latinoamericanos, la región sufre otra transformación sorprendente: el establecimiento y consolidación de gobiernos electrónicos y la emergencia de movimientos sociales en internet, que comienzan a recrear escenarios inéditos de mutación institucional y de ciudadanías a través de los medios informáticos. Efectivamente, en el inicio del siglo XXI, la expansión de las prácticas digitales, aquellas que se nutren del avance acelerado de las tecnologías de la información y las telecomunicaciones, han tocado la movilización social y al Estado, configurando un componente novedoso del proceso de renovación de ciudadanías, de búsqueda de nuevos esquemas de representación y participación política, y de un modelo de gobierno para la era digital.

Para los estudios políticos, estos procesos acelerados y altamente tecnológicos plantean serios retos de aproximación. La presencia de dispositivos electrónicos y digitales enlazados a nuevas conductas sociológicas, la problemática de incorporar nuevas definiciones y conceptos provenien-

GOBIERNOS ELECTRÓNICOSY ACCIÓN COLECTIVA ATRAVÉS DEL INTERNET: DINÁMICAS EN LA REGIÓN ANDINA 
tes de las ingenierías, sumados a la celeridad de los procesos implicados, generan un campo de arenas movedizas para el análisis político.

Pero se tiene una ventaja, el ritmo incremental de los fenómenos que involucran las tecnologías informáticas es de tal magnitud, que no hace necesario buscar muy lejos las evidencias de los cambios igualmente acelerados y profundos que ha infligido sobre el Estado y los ciudadanos. En la región andina, esta denominada conectividad se expresa en usos tan cotidianos y diversos como son la lectura del periódico online y el pago de impuestos o planillas de seguridad social a través del internet. Pero estas evidencias tan cerca de nosotros nos llevan inevitablemente a preguntarnos por los efectos que esta conectividad trae sobre las vulnerables democracias andinas.

A tales consideraciones, este artículo plantea revisar dos dinámicas destacables que surgen de ese «toque» entre tecnologías informáticas, Estado y ciudadanos, teniendo en mente el internet como «medio acuoso» de tal combinación y la región andina como campo de observación: la primera, la implementación y función de los Ilamados gobiernos electrónicos; la segunda, las nuevas formas de organización y movilización social a través del internet.

Para abordar estas dinámicas sugerimos la siguiente tesis: la implementación de los gobiernos electrónicos en la región andina responde a procesos concretos de modernización y ajuste de la administración pública en los Estados a fin de enfrentar un mundo global, pero que aún no permiten generar experiencias concretas de apertura o novedad democrática, de participación y toma de decisión ciudadana a través del internet. Por su parte, los principales movimientos sociales del último lustro en la región andina se presentan como actores particularmente atraídos y dinámicos en el uso de plataformas informáticas para posibilitar experiencias que se pueden interpretar como apertura de nuevos espacios de participación y movilización, que renuevan su accionar sociopolítico y suponen expectativas para la democracia en la región.

No es nuestra intención detenernos a analizar los aspectos técnicos y normativos de los gobiernos electrónicos, ni la naturaleza política de los movimientos sociales y las repercusiones de su acción colectiva en el mundo «real». Más bien intentamos recrear ese «toque», definir rasgos y proponer algunas reflexiones.

\section{LOS ESTADOS ANDINOS FRENTE A LA ERA DEL INTERNET}

\subsection{Contexto de emergencia}

El inicio del nuevo siglo en los Estados andinos (como en el resto de Latinoamérica) fue recibido con la adopción discreta de unas políticas de tendencia internacional, específicas para lidiar con la 
tecnología informática, conocidas como Agendas de Conectividad'. Tales políticas establecían las normas de regulación, privatización, acceso e infraestructura de las tecnologías informáticas y de telecomunicaciones; además definían los ejes del Estado frente a la orientación y masificación de tales tecnologías: programas como Telesalud en Ecuador, Computadores para Educar en Colombia, Entrenamiento en Tecnologías de la Información en Perú, Generación de Contenidos Informáticos en Venezuela, hacen parte de esas políticas. La germinación de tales agendas en la región fue un proceso determinado por cuatro procesos que le antecedieron:

\subsubsection{El espíritu de las reformas neoliberales}

Las reformas conocidas como neoliberales tuvieron su génesis en la región desde los años de Pinochet en Chile (1973-1988), Carlos Andrés Pérez en Venezuela (1988-1992), Jaime Paz en Bolivia (19891993), Fujimori en Perú (1990-2000), Durán en Ecuador (1992-1996) y César Gaviria en Colombia (1990-1994). La periodicidad de su implementación es relativa, pero su marco conceptual para América Latina se ubica en el célebre «Consenso de Washington» o «Lo que Washington entiende por reformas", redactado en 1989 por el economista John Williamson en base a opiniones recogidas en una obra colectiva de la que fue editor «»La condicionalidad del FMl», MIT, 1983". El decálogo original que planteó Williamson agrupaba tres líneas principales: la liberalización doméstica, la prudencia macroeconómica y la orientación al exterior, que se identificaron en la práctica con los procesos de apertura económica. Luego fueron agregados nuevos puntos, como el incremento del control y de la participación ciudadana, la rendición de cuentas, la descentralización, los marcos regulatorios, la reforma a la justicia, las nuevas formas de participación, que en la práctica se reconocieron en los procesos de modernización del Estado.

Las reformas neoliberales no formularon aspectos directos sobre la conectividad o el uso de la informática; incluso la aparición de las Agendas de Conectividad en la región se dieron en el marco de gobiernos críticos o moderados frente al neoliberalismo: Chávez en Venezuela, Toledo en Perú, Noboa en Ecuador, Pastrana en Colombia, Eduardo Frei Ruiz-Tagle en Chile. El vínculo primario entre estas reformas y las Agendas de Conectividad estaría más ligado al comportamiento del Estado frente a dos asuntos clave y complicados bajo su responsabilidad: el monopolio sobre las telecomunicaciones y las políticas contra la pobreza.

El monopolio sobre las telecomunicaciones de los Estados en el periodo de la Guerra Fría era un asunto incuestionable. El servicio de la comunicación era considerado monopolio natural del Estado, el cual cumplía el papel de construir la infraestructura y regular su funcionamiento. En la región andina, la mayor parte de los países optó por la empresa pública estatal para la incorporación de la radio hacia los años treinta y la televisión en los sesenta.

\footnotetext{
${ }^{1}$ Agendas de Conectividad en la región andina: un camino hacia la sociedad de la información y el conocimiento (2001) de Ecuador, El salto a internet-camino a la sociedad del conocimiento (2000) de Colombia, el Plan de Desarrollo de la Sociedad de la Información en el Perú (2001) (2005), y el Plan Nacional de Telecomunicaciones de Venezuela (2000).
}

GOBIERNOS ELECTRÓNICOSYACCIÓN COLECTIVA ATRAVÉS DELINTERNET: DINÁMICAS EN LA REGIÓN ANDINA 
Las reformas neoliberales de los años noventa rompieron esa tendencia al considerarse que el Estado no era el único responsable en la construcción de redes de telecomunicación, que la telefonía ya no era el único producto de la telecomunicación y que las empresas operadoras deberían desarrollar economías de variedad y recibir competencia desde el exterior.

Desde los años ochenta las tecnologías de microondas, los recursos satelitales y las redes internacionales y transoceánicas de fibra óptica en manos de gigantes corporativos como AT\&T, Bell, Sprint, ya amenazaban el monopolio natural del Estado. No obstante, los esquemas de empresa estatal subsistieron hasta mediados de los noventa en varios países de la región, bajo el doble argumento de la razón estratégica de las comunicaciones y la debilidad de los mercados, los cuales se volvieron obsoletos frente a la mayor penetración del internet, los satélites y el mayor impacto de las telecomunicaciones en el crecimiento económico.

A finales de los noventa, en los casos de telefonía local y de larga distancia se rompieron los monopolios sin ninguna discusión y se hizo el tránsito hacia estructuras duopólicas o triopólicas, al mismo tiempo que aparecieron nuevos operadores y las grandes ciudades andinas se aprestaron a afrontar un oligopolio de empresas extranjeras, especialmente en el negocio de comunicación celular e internet.

Para los años dos mil, los monopolios estatales en las telecomunicaciones eran historia. Sin embargo, los gobiernos de la región eran conscientes de que las tecnologías de la información trascendían la etapa de la radio, el teléfono y la televisión.

«...Las Tecnologías de la Información son herramientas que permiten el desarrollo de una nueva economía, la construcción de un Estado más moderno y eficiente, la universalización del acceso a la información, y la adquisición y utilización eficaz del conocimiento, todos estos elementos fundamentales para el desarrollo de la sociedad moderna. Sin embargo, así como un buen uso de las tecnologías de la información puede constituirse en un elemento generador de conocimiento, crecimiento e igualdad social, su inadecuada utilización puede acarrear efectos nocivos para el país...» (Agenda de Conectividad colombiana, 2000).

La oportunidad era única, había que colocar al Estado de nuevo en el centro del proceso, pero esta vez no como proveedor, sino como máximo consumidor y apropiador de tecnologías informáticas y de telecomunicaciones (Declaración de Quebec, Cumbre de las Américas, 2001).

Por su parte, las políticas contra la pobreza de los años noventa fueron tomadas como prototipo de las posteriores políticas para enfrentar la brecha digital a través de las Agendas de Conectividad. Los elementos que se destacan en estas políticas son la selección e incorporación de los beneficiarios (infopobres), la alianza con el sector privado y la concepción estadística para la reducción de las desigualdades sociales (estadísticas de acceso). El trabajo de Dagmar Raczynski, «Overcoming 
Poverty in Chile», hace un buen análisis acerca de las políticas neoliberales de reforma del sector público y su impacto sobre las políticas destinadas al tratamiento de la pobreza y posteriormente al estrechamiento de la brecha digital. Según ese trabajo, estas políticas se basaron en el principio de subsidiaridad del Estado que emergía de un proceso previo de reducción de su tamaño a través de incorporación tecnológica, transferencia o contratación al sector privado de procesos altamente técnicos (como el conteo de votos en las Registradurías), privatización de parte importante de los servicios públicos, la descentralización ministerial y la transferencia tanto de la educación, la salud, las obras de infraestructura y telecomunicaciones a las municipalidades. Como lo observa Saskia Sassen (Sassen 2007: 165), esto dio pie a otro fenómeno: las comunidades urbanas fueron sacudidas por una reestructuración política, económica y cultural, que filtraba sectores con acceso y sin acceso a la riqueza y a la digitalización del mundo, pero esa es otra historia.

\subsubsection{La liberalización económica para importar}

La liberalización económica en Ecuador, Perú y Colombia produjo una dominación total de las importaciones de equipos (teléfonos, conmutadores, radioteléfonos, computadores, módems). Los grandes empresarios nacionales lo hacían mediante licencias, pero también se podían importar equipos y todo tipo de tecnología informática sólo con poseer una tarjeta de crédito. La producción nacional de dispositivos de telecomunicaciones se reduce al ensamble de centralitas en Colombia (ITI), de teléfonos de mesa con tecnología Siemens en Ecuador y las centrales de conmutación Ericsson en Chile.

La asimilación de los enormes cambios tecnológicos durante los años noventa en la región se dio de forma gradual de acuerdo al ingreso per cápita de los países (Katz, 1999: 3-48). Por ejemplo, en promedio, la densidad telefónica en los países andinos de mejor entrada percapita en los noventa «Chile, Colombia y Venezuela» pasó del 8,8\% en 1990 al 13,9\% en 1995, al 20,5\% en el 2000. Esto se originó principalmente por la importación masiva de dispositivos de cómputo y telecomunicaciones, el incremento en los suscriptores al internet telefónico y a la televisión por cable, el tráfico de telefonía celular y las nuevas inversiones en servicios de valor agregado. En telefonía celular, los incrementos fueron del orden del $90 \%$ en usuarios y del $80 \%$ en accesos a internet (Katz, 1999: 18). Las inversiones en servicios de valor agregado paralizaron su expansión en los operadores de "beeper» o buscapersonas; las afiliaciones y utilización del internet y las redes de tratamiento de datos era el nuevo negocio.

\subsubsection{La moda del internet}

La historia del internet es reciente para los países andinos. Comienza en los años noventa con la incursión del internet público y experimental en las universidades centrales y que a comienzos de los años dos mil, en medio de los efectos de las políticas neoliberales, es privatizado y encargado de su cobertura a las empresas privadas. A decir verdad, con ayuda de la piratería de software y la clonación de computadores, hacia finales del 2001 ya el internet, si bien no era masivo, sí constituía un motor transformador en las relaciones socioeconómicas y culturales de las principales ciudades andinas con el mundo (Latin American Newsletters, 2001). Nacieron los café-internet y se 
popularizó el e-mail, el chat y los buscadores. También fue el auge de las carreras asociadas a la informática. Asimismo, el avance del comercio electrónico y el ocio digital casero fue cada vez mayor en las ciudades².

No obstante, la penetración de internet en sectores de la población fue y ha sido irregular. Los altos costos de la conectividad en regiones apartadas (especialmente en zonas rurales y de frontera), la baja densidad de computadores en los sectores marginados y la falta de apropiación en el uso de estas tecnologías siguen siendo retos vigentes en la región ${ }^{3}$. Las cifras globales respaldan esa afirmación: Europa y América del Norte concentran el $64 \%$ de los usuarios de internet en el mundo, el Asia emergente cerca del 25\%, América Latina representa apenas un 6\% y África y Oriente Medio tan sólo el $2 \%$. Brasil y Chile, los países de Latinoamérica con más acceso a la red, cuentan con poco menos del 30\% de la población «online»; Venezuela, Colombia, Ecuador y Bolivia con un poco más del 15\% (UIT, 2007).

El internet emergió de forma tímida en la región andina, público pero sin apoyo directo del Estado, jalonado al ritmo de las redes universitarias. Los inicios del internet en Colombia se hallan hacia 1990, cuando se conformó la Red Universitaria de Colombia «Runcol», en la cual participaban las principales universidades del país con apoyo del Instituto Colombiano para el Fomento de la Educación Superior «ICFES». Dicha red, liderada por el nodo de la Universidad de los Andes «Andescol», contaba con una infraestructura para operar con la red BitNet «Because It's Time of NETworks» de universidades de los Estados Unidos. Para 1993, el Instituto Colombiano de Ciencia y Tecnología «Colciencias» y el ICFES deciden conformar la Red Colombiana de Ciencia y Tecnología «Cetcol». Esta red comenzó a prestar el servicio público de internet desde 1996 y la Universidad de los Andes asumió el servicio de registro de dominios (.CO) «norma internacional de enlace web para Colombia», impulsando el proceso de inserción del país a los estándares internacionales de internet a mediados de los años noventa. Pero es sólo hasta 1999 cuando, debido a la gran demanda de conexión en el país, se afianzaron varias empresas del sector privado y de telefonía pública (Colomsat, Andinet, Telecom, ETB, Gratis1, Tutopia, entre otros) en los servicios de conectividad. En los otros países de la región la línea del proceso, con sus correspondientes actores, fue muy similar ${ }^{4}$.

\subsubsection{El Y2k o pánico informático de fin de siglo}

El problema de programación de las memorias de datos integradas a los computadores producidos antes de 1995, que carecían de las dos primeras cifras para representar los años y que eran indis-

\footnotetext{
${ }^{2}$ América Economía Inteligente (2005). Entre 2000 y 2005, el comercio electrónico en América Latina creció a tasas promedios del $60 \%$. Se estima que el comercio electrónico crecerá en la región a tasas de $40 \%$ anual entre 2006 y 2010.

${ }^{3}$ El Intermediate Technology Development Group «ITDG». El ITDG ha producido un Cd-Rom denominado Apropiación de Tecnologías de la Información y Comunicación en América Latina que expone en detalle este punto.

${ }^{4}$ Puede verse una reconstrucción de la historia del internet latinoamericano en «Pioneros «Internet de América Latina». La historia contada por sus protagonistas», en http://interred.wordpress.com/
} 
pensables para distinguir entre los años 1900 y 2000, produjo las primeras políticas estatales concretas frente al manejo de la informática. Según las estimaciones de IBM en 1996, más de 500.000 sistemas informáticos integrados en la región andina operarían con fecha incorrecta el año 2000 (30 millones a nivel mundial), si no se tomaban los correctivos. Todos los gobiernos de la región abordaron el asunto a mediados de 1998 cuando las entidades más sistematizadas para ese momento, la recaudación de impuestos y la banca, expresaron sus preocupaciones. De esa forma, los organismos del Estado y las principales empresas privadas implementaron un amplio programa de actualización informática y reprogramación financiada por el Banco Interamericano de Desarrollo (BID América, 1998). El costo de solucionar el problema en la región andina ascendió a 300 millones de dólares.

A partir de ese momento y en lapso de tres años, cada uno de los Estados de la región se equipó con programas, políticas y estrategias coordinadas para manejar de forma permanente los aspectos relevantes, para el gobierno y la sociedad, de las nuevas tecnologías de la información; así fueron formuladas las Agendas de Conectividad.

\subsection{Las Agendas de Conectividad: políticas de Estado para la sociedad de la información}

Las Agendas de Conectividad constituyen una síntesis de los elementos políticos, ideológicos y tecnológicos, globales y locales, que orientan el «toque» y los procesos de transformación estatal y social en curso. Aunque las agendas andinas comparten similitudes en sus objetivos y metas, son políticas de cobertura esencialmente nacional, desarticuladas de la institucionalidad regional, como por ejemplo la Comunidad Andina (CAN). En el caso de Chile, Colombia y Ecuador, las políticas fueron formuladas por equipos técnicos del gobierno, ubicados preferencialmente en los ministerios de comunicaciones o en las vicepresidencias. En Perú y Bolivia hubo procesos participativos con las empresas y organizaciones sociales; no obstante estos mismos grupos retiraron su apoyo a las estrategias tras las crisis políticas de los primeros años del dos mil. En Venezuela la agenda emergió de un proceso coordinado por los principales ministerios del gobierno.

Todas las agendas hacen énfasis en la construcción de una sociedad de la información, un concepto que interpreta obviamente el poder de la información en un mundo global. Como expresión, la sociedad de la información proviene del entorno europeo, después de que el Libro Blanco de Jacques Delors (1993) Crecimiento, Competitividad y Empleo y el Informe liderado por Martin Bangemann con recomendaciones para el Consejo Europeo, Europe and the Global Information Society (1994), empezaran a utilizarla como indicación de una transición hacia un estadio ideal, denominado a su vez como sociedad del conocimiento. Como objetivo, la sociedad de la información recoge la necesidad de plantear políticas públicas de desarrollo, promoción y universalización de las tecnologías informáticas y de las telecomunicaciones. La formula ofrecida por la Comisión

Europea para llegar a una sociedad de la información, a través de los documentos citados, incidía en varios puntos (Comisión Europea, 1994: 54-65):

GOBIERNOS ELECTRÓNICOS Y ACCIÓN COLECTIVA ATRAVÉS DEL INTERNET: DINÁMICAS EN LA REGIÓN ANDINA` 
«...Avance hacia las comunicaciones satelitales y digitalizadas, nuevas leyes, un nuevo sistema educativo, promoción de redes sociales virtuales, programas de desarrollo en tecnologías y potenciación de los aspectos, económicos, políticos, sociales y culturales a través de tecnologías como el internet».

Ya que los logros parciales de las Agendas de Conectividad en la región se concentran en la obtención de equipos de cómputo usados para la educación, en el mejoramiento de la competitividad de algunas empresas nacionales a través de alivios tributarios en equipos y software informáticos, y en legislaciones avanzadas para el comercio electrónico, no podemos aún percibir el avance hacia las sociedades de la información y del conocimiento. Por el momento es un slogan, sin mayor digestión conceptual, sin evidencia empírica, pero que acompaña firmemente los objetivos de las Agendas de Conectividad.

En este punto, desde la reflexión sociopolítica, podemos advertir tres cosas claras que han dejado estos años de conectividad en la región: la primera, que la reciente expansión y generalización del uso de las tecnologías informáticas y de las telecomunicaciones han influido de manera significativa en la transformación de las empresas, instituciones e individuos contemporáneos (Dias Batista, 2004; Mälkiä, 2004). La segunda, que estas transformaciones no se están dando de manera uniforme y que los avances realizados en términos de aprovechamiento de estas tecnologías en los ámbitos de la democracia y la participación socio-política se encuentran muy detrás de los relacionados con el campo del comercio, el ocio y la comunicación personal (Trechsel, 2003: 24). La tercera, desde una interpretación Cepalina, es que el acceso a las tecnologías de la información responde igualmente a las dinámicas de centro-periferia (Grimshaw, ITDG, 2003: 15). En consecuencia, estas tecnologías mantienen su carácter foráneo en muchas pueblos andinos (desde los programas que las controlan hasta los dispositivos con los que se interactúa), y reproducen las asimetrías estructurales que afectan principalmente a las poblaciones o regiones menos articuladas a la economía internacional, es decir, allí donde la adquisición del proceso técnico y el cambio tecnológico es mucho más lento y costoso.

Pero eso sí, las agendas andinas han sido extraordinariamente exitosas en implementar con celeridad e impacto un modelo de técnicas y políticas para conectar el gobierno y las instituciones estatales entre sí, y con otras organizaciones y personas, especialmente mediante páginas y portales web. El gobierno electrónico, gobierno digital o gobierno en línea, como se le denomina indistintamente en la región, es el producto más patente de una década de políticas sobre conectividad en los países andinos.

Según el ranking internacional realizado por el estudio «Improving Technology Utilization in Electronic Government around the World», entre 198 países y que mide la efectividad en la implementación informática y uso del internet dentro del Estado, para el 2008 Colombia ocupaba el puesto 23, Chile el puesto 27, Perú el 58, Ecuador el 97, Bolivia el 114 y Venezuela el 125. ¿Qué significa la implementación informática y el uso del internet dentro del Estado? Veamos. 


\subsubsection{El gobierno electrónico atrás de la pantalla}

Podríamos afirmar a priori que la implementación de modelos informáticos de relación entre el Estado y el ciudadano podría significar un avance para contrarrestar ciertos vacíos sociopolíticos que nos dejan estos años de euforia cibernauta y multimedia. Es decir, generar nuevas formas de acción y participación política, de movilización con nuevas herramientas, tal como podemos interactuar en un videojuego con personas conectadas a la red. El avance no sólo tiene impacto en la manera de hacer un trámite o pagar un servicio por internet, sino que tiene profundas incidencias en la forma en que es posible llevar a cabo la acción pública y particularmente transforma lo que se conoce como democracia representativa.

Los argumentos a favor de la introducción de tecnologías informáticas en las actividades de los gobiernos y sus ciudadanos llevaron al surgimiento de las iniciativas de gobierno electrónico. Sin embargo, la práctica viene a relativizar ese logro, mostrando cómo, con tan sólo nuevos soportes digitales, las organizaciones públicas y la democracia no pueden superar sus vicios o sus limitaciones. Así, quienes visitamos los portales de gobierno electrónico en nuestros países y tenemos expectativas de estar a un paso de incidir dentro de las diversas decisiones que nos incumben como ciudadanos, nos encontramos a menudo con importantes barreras, límites de carácter procedimental y organizativos, siendo con frecuencia la tecnológica la menos importante (Criado \& Ramilo, 2001: 20).

¿Por qué se da este sinsabor? Porque la razón de ser de los gobiernos electrónicos está atrás de la pantalla y no frente a ella. Eso quiere decir que el gobierno electrónico es, en esencia, un modelo de gestión pública para mejorar las actividades intraestatales, que se articula en torno a tres dimensiones o roles de las administraciones públicas (prestación de servicios, fomento de la consulta y aplicación de normas internacionales como transparencia, finanzas y contratación).

Los estudios de Aberbach y Rockman (1999) y Olías de Lima (2001) identifican concretamente las razones:

- Cambio del entorno. Se trata de subrayar el uso de la tecnología informática por parte del Estado para afrontar el fenómeno de la globalización, la fluidez del entorno, la internacionalización de los mercados y el desafío subnacional; no se conviene congestionar más el sistema con demandas democráticas.

- Expansión de la revolución gerencial. Creencia de la nueva administración pública en las posibilidades de conseguir resultados mediante el uso de técnicas apropiadas y la disponibilidad de un elenco de instrumentos susceptibles de utilización en las más variadas circunstancias.

- Posicionamiento en internet. De la misma forma como Google o Microsoft pueden ofrecer servicios online en el terreno ofimático, el Estado pone a disposición sus servicios en internet. Esto no implica llevar la toma de decisiones de la empresa o el Estado por el mismo camino.

Autores como Hughes (1998) sistematizan los imperativos para implantar gobiernos electrónicos señalando determinados aspectos: primero, la existencia de una teoría económica que parece ofre- 
cer más precisión, utilidades y consistencia que las nociones tradicionales de administración pública. Segundo, un claro ataque contra los métodos tradicionales del sector público. En tercer lugar, el hecho de que la gestión y la eficiencia del sector público se están midiendo y afectan a la economía privada y a la competitividad nacional, de forma que esa preocupación se concreta en aplicar modelos de gestión documental eficiente, tramites sin filas, bases de datos, comunicación instantánea, entre otros.

Efectivamente, los administradores públicos son los primeros en recibir el impacto de las tecnologías dentro del Estado. Diversos estudios demuestran que las administraciones públicas nunca fueron reacias al uso de las tecnologías para mejorar o subir de estatus sus procesos internos. De hecho, desde los primeros imperios (Egipcio, Persa, Chino) se mantuvo a los administradores públicos muy cercanos a las más notables invenciones de su respectiva civilización (Bellamy y Taylor, 1998; Kraemer y Norris, 1996). En lo que respecta a las tecnologías informáticas y el Estado moderno, desde las grandes guerras mundiales, la burocracia ha sido usuaria activa de cuanta tecnología para la oficina surja (máquinas de escribir, grapadoras, tintas invisibles, luces ultravioletas, proyectores de acetato, entre otras.) (Castells, 1997).

\subsubsection{El gobierno electrónico frente a la pantalla}

Una revisión de los portales de gobierno electrónico de los países de la región (gobiernoenlinea.gov.co, gobiernoenlinea.ve, presidencia.gov.ec, ongei.gob.pe, chileclic.gob.cl), nos permite revelar no un nexo político, sino un nexo de consumo entre el ciudadano (usuario) y el gobierno (proveedor). Todo esto se da a través de plataformas web que contienen información básica sobre el Estado, hipervínculos a las entidades oficiales, un catálogo de trámites/servicios online-offline y un correo de quejas y solicitudes. El catálogo de trámites/servicios online-offline diferencia dos tipos de usuarios: personas naturales y personas jurídicas. En algunos casos, como el colombiano y el venezolano, se agrega un tercer usuario: el funcionario público.

El frente a la pantalla expresa rasgos de un modelo de democracia y gobierno digital que promueve la introducción de los mecanismos y la lógica de mercado en la gestión de los servicios del Estado. Como señala Bellamy (2004), es la transición de racionalidades públicas hacia racionalidades más económicas mediante la interacción gobierno-ciudadano a través del internet.

Como heredero de una concepción de la democracia liberal en la cual los intereses de los individuos tan sólo serán defendidos por ellos mismos en la misma medida que tengan capacidades para hacerlo, el gobierno electrónico se asegura que todos los ciudadanos-usuarios tengan los mismos derechos y posibilidades. Dentro de la plataforma web esto implica una gran capacidad de demandar y generar información sobre la gestión del Estado. Este modelo establece como forma característica de procedimiento el énfasis en un adecuado flujo de información para los consumidores, que les permita desarrollar las capacidades de elección entre los distintos servicios del Estado, determinando cuáles funcionan y satisfacen al consumidor y cuáles no. Esto convierte a los ciudadanos con acceso a internet en «poderosos clientes del gobierno». 
Como planteábamos al principio de este artículo, los efectos que la conectividad trae sobre las vulnerables democracias andinas aún son difíciles de precisar, pero ya abren un debate. Las propiedades y potencialidades de estas tecnologías permiten fantasear sobre multitud de modelos y posibilidades para interactuar con los gobiernos y acercarnos a democracias más directas, sin importar la multitud de colectividades o individuos que la compongan.

Es evidente que los países andinos tienen problemas más graves que resolver, y el ejercicio de una democracia plena a través de innovaciones informáticas puede esperar, lo cual no es impedimento para que el desarrollo de tecnologías como el internet no encuentre otras posibilidades, otras formas de activar la participación ciudadana y la acción colectiva. Eso es tarea, por ahora, de los movimientos sociales.

\section{LOS MOVIMIENTOS SOCIALES ANDINOS EN INTERNET}

El acercamiento de los movimientos sociales a la era del Internet tiene antecedentes más amplios frente a las experiencias de gobierno electrónico. En Latinoamérica, el antecedente más destacado del activismo en internet es el movimiento mexicano Zapatista "EZLN» en contra del neoliberalismo (Conferencia Intercontinental por la Humanidad y contra el neoliberalismo en Chiapas, 1996). Poco después aparecieron otras iniciativas en el ciberespacio, como la del Movimiento de los Sin Tierra "MST", brasilero, y la Coordinadora Latinoamericana de Organizaciones del Campo "CLOC» (1997). A ellos se sumaron otras redes internacionales de gran importancia, como la Acción Global de los Pueblos "AGP», la Asociación por una Tasa a las Transacciones Financieras Especulativas para Ayuda a los Ciudadanos/as "ATTAC», la Marcha Mundial de las Mujeres, la Campaña Continental contra el ALCA, el Focus on the Global South, entre otros.

Hacia 1999 emergieron las grandes plataformas que articulan en la actualidad gran parte de los movimientos regionales. En su mayoría fueron concebidas como espacios de coordinación y articulación con otras redes independientes y apuntaron a asegurar la mínima presencia de los movimientos sociales en internet. Veamos a continuación algunas de las principales plataformas.

\subsection{Plataformas de movimientos sociales andinos en internet}

2.1.1. La Comunidad Web de Movimientos Sociales "CWMS" ${ }^{5}$

La iniciativa de desarrollar la CWMS en Latinoamérica surgió de una relación de colaboración, acompañamiento y asesoría en comunicación de la Agencia Latinoamericana de Información «ALAl» con diversas organizaciones y coordinaciones sociales, entre ellas la CLOC y la Red de Mujeres Afrolatinoamericanas y Afrocaribeñas «RMAA». Posteriormente se integró con organizaciones indígenas y comunales del Ecuador, Perú, Colombia y Bolivia.

\footnotetext{
${ }^{5}$ Información recolectada a partir de Latin American and Caribbean Social Movements and the Internet (ALAI) - Phase II, 2004, www.alai.org

GOBIERNOS ELECTRÓNICOSYACCIÓN COLECTIVA ATRAVÉS DEL INTERNET: DINÁMICAS EN LAREGIÓN ANDINA
} 
Este espacio comunitario fue habilitado en septiembre de 1999 y consiste en dos portales principales:

- $\quad$ América Latina en Movimiento (www.alai.org), que consiste en un espacio de información organizada sobre movimientos sociales y coyuntura latinoamericana. Está bajo responsabilidad directa de la ALAI y contiene tres componentes principales: una base documental clasificada por temas, un servicio de noticias y la revista América Latina en Movimiento, en formato digital. Este sitio proporciona, por una parte, un servicio de comunicación a los movimientos sociales y a otras organizaciones preocupadas por temas sociales de la región; y, por otra, es una plataforma de instrucción práctica para los movimientos interesados en aprender a estructurar un sitio web y tener presencia en internet a partir de una estrategia sencilla de comunicación y uso de herramientas en la red.

- $\quad$ MINGA (www.movimientos.org), que contiene los espacios autónomos de las diferentes coordinaciones y redes sociales participantes. Consiste en un portal en tres idiomas, bajo el lema «Unidad en la Diversidad», donde cada movimiento social participante aloja su sitio de manera autónoma. Cada movimiento puede a su vez abrir espacios para sus organizaciones miembros (réplicas de su sitio web nacional o enlaces con otras organizaciones). También se abren espacios para dinámicas conjuntas y se comparten algunos servicios comunes, como el mecanismo de búsqueda, campañas, eventos, alertas, entre otros. En dicho espacio puede reconocerse una fuerte participación de movimientos bolivianos, como el de los Ayllus y Markas del Qullasuyu, y la confederación de pueblos indígenas de Bolivia «CIDOB». También se encuentra la Organización Nacional Indígena de Colombia "ONIC» y la Escuela de Mujeres Dolores Cacuango del Ecuador, entre otras organizaciones.

Desde las páginas web de la CWMS se adelanta la campaña continental contra el ALCA, la campaña continental contra la militarización estadounidense en América Latina y el Caribe, la campaña internacional del jubileo Sur contra el pago de la deuda externa, la campaña internacional de la Vía Campesina y se articula con actividades en torno al Foro Social Mundial.

\subsubsection{Los medios periodísticos independientes «Indymedia» ${ }^{6}$}

Indymedia es una red que gestiona noticias e informaciones sobre movimientos sociales y problemáticas de diversos países. A partir de un portal que alberga la central del proyecto Indymedia (www.indymedia.org), se despliega una serie de hipervínculos nacionales (indymedia.org.co, indymedia.org.ve, por ejemplo). En la actualidad, Indymedia incorpora 91 centros de información localizados así: 2,1\% en África; 20,87\% en Europa; 3,2\% en Asia; 12,08\% en América Latina; 6,5\% en Australia-pacífico; $12,08 \%$ en Canadá y 42,85\% en Estados Unidos. Los portales de Indymedia contienen narraciones en texto, video, fotografía y/o audio, y en el idioma de cada país. A su vez, cada organización responsable en cada país actualiza los contenidos.

\footnotetext{
${ }^{6}$ Sobre el desarrollo de Indymedia ver: Fleischman Luciana, Internet y movimientos sociales: comunicación en los movimientos de resistencia global, IAMCR, 2004.
} 
La plataforma se inscribe dentro de la tendencia periodística de contra-información y comunicación alternativa, y en ese sentido su accionar en internet se dirige a vulnerar los contenidos de los medios tradicionales de comunicación. Muchas veces este accionar va acompañado de un proyecto político alternativo en cada país, tendiente a apoyar movimientos políticos y hacer frente a discursos dominantes o hegemónicos.

\subsubsection{Los altermundialistas ${ }^{7}$}

Los altermundialistas son redes internacionales de oposición a la globalización neoliberal, a la vez que son una expresión de la globalización. Son los movimientos nacidos en el internet ya que éste les resulta imprescindible para su actuación y para la redimensión de sus territorios de influencia y acción (Castells, 2001). La lógica de articulación en red, el manejo de herramientas tecnológicas y el control espacio/tiempo global aparece en la genética de estos movimientos.

En América Latina, cientos de portales articulados a la red del Foro Social Mundial coordinan las convocatorias, campañas, manifiestos, eventos y actos públicos antiglobalización a través de webs, news, correo, listas de distribución, ftp, blogs, foros, entre otrow. Además, portales como www.nodo50.org y www.sindominio.net ofrecen servicios gratuitos de alojamiento de páginas web para movimientos latinoamericanos y mantienen una comunidad que desarrolla programas informáticos libres para el uso de las organizaciones sociales.

\subsubsection{Las comunidades virtuales: Myspace y Facebook}

La creciente interacción social a través del internet ha permitido el éxito de portales que publican perfiles personales de usuarios dentro de una red de millones de personas que se agrupan y comparten información de acuerdo a sus afinidades: blogs, fotos, videos y música, además de una red de mensajería y búsqueda que permite comunicarse a unos usuarios con otros sin salir del portal. Aunque sus orígenes se relacionan con las aristocráticas fraternidades universitarias de Estados Unidos, portales como Myspace y Facebook ganaron gran popularidad hacia el año 2005 y se extendieron dentro de jóvenes y profesionales de todo el mundo, hasta alcanzar cerca de 47 millones de usuarios en 2007. Colombia es el país de Latinoamérica con más usuarios registrados en Facebook (488.520) (www.facebook.com).

A diferencia de las ya mencionadas plataformas, comunidades virtuales como Myspace no se desarrollaron con el objeto explícito de potenciar la movilización social, no obstante, contienen herramientas de comunicación más potentes que junto con una extensible base de datos le han dado un reciente protagonismo. Son un núcleo de convocatoria y coordinación de acciones globales, entre las que se destacan la red de sanción social contra el abuso sexual infantil, el grupo Facebook del Foro Social Mundial, la red civil anticorrupción en México y los grupos de movilización contra las Farc y contra los Paramilitares en Colombia.

\footnotetext{
${ }^{7}$ Sobre los altermundialistas ver: Lago Martínez Silvia, «los movimientos sociales: altermundialización y el activismo en internet», en www.nodo50.org.
}

GOBIERNOS ELECTRÓNICOSYACCIÓN COLECTIVA ATRAVÉS DEL INTERNET: DINÁMICAS EN LA REGIÓN ANDINA 
En síntesis, a través de estas plataformas y herramientas informáticas diversos movimientos de la región han venido experimentando un primer acercamiento a la colaboración informativa, a la práctica de difusión en internet, al intercambio y la reflexión entre las organizaciones y los individuos conectados a la red global. Apreciemos algunas orientaciones y estrategias concretas de la acción colectiva en internet aplicada por actores de la movilización en Ecuador, Venezuela y Colombia.

\subsection{Aproximación a las iniciativas en la región andina}

\subsubsection{Los ciberindigenas}

La Confederación de Nacionalidades Indígenas de Ecuador «CONAIE» es el actor principal de las movilizaciones indígenas en Ecuador. Inició su presencia en internet hacia el 2001 con el portal www.conaie.org, y junto con el sistema indymedia, la red Voltaire y la ALAI, desarrolló un proceso de articulación a planes y componentes informáticos, compartiendo recursos y desarrollando iniciativas conjuntas.

La CONAIE mantiene una estrategia clara de adopción y uso del internet dentro de su organización. Tres orientaciones definen este accionar:

- $\quad$ Una, la consolidación de cuadros dirigentes indígenas, especialistas en tecnologías y herramientas de la comunicación, que puedan orientar y tomar decisiones que conciernen a las plataformas tecnológicas. Esto se manifiesta en la formación de activistas nativos en tecnologías web, para que le den soporte a los sistemas y desarrollen labores especializadas. Dicha orientación ha llevado a la instrucción técnica e ideológica de los encargados de estas plataformas, de tal forma que garanticen su permanencia al interior de la organización. La CONAIE evita depender de técnicos externos a la organización (consultores o técnicos no indígenas), así como de generar choques entre los dirigentes políticos de la organización y los dirigentes técnicos.

- Dos, la búsqueda de apoyo financiero en diversas fuentes de cooperación internacional, en organismos del Estado, en recursos propios obtenidos mediante la prestación de servicios de información y en el aporte de voluntarios a nivel nacional e internacional. Las plataformas tecnológicas de la CONAIE reciben recursos principalmente de los gobiernos de Cuba y Venezuela, así como de las organizaciones indígenas y activistas altermundialistas en Norteamérica y Europa.

- Tercera, el uso de software libre, imprescindible para el sostenimiento financiero y técnico de la plataforma. La CONAIE promueve frontalmente una alianza para el uso del software libre en la región. Este hecho es clave, ya que el debate sobre el software libre como camino hacia el desarrollo económico y social es generalizado dentro de los movimientos sociales que mantienen presencia en internet (Mena, 2002: 14).

\subsubsection{Los ciberbolivarianos}

Los movimientos sociales en Venezuela irrumpieron con fuerza en internet a partir de 2002, luego del golpe de Estado contra Hugo Chávez. Como lo explica Ramonet, 
«Los medios de comunicación tradicionales instalaron una República del Silencio...allí el Internet desempeñó un papel fundamental, Ilenando el vació de información del primer golpe de estado mediático del siglo XXI», (Ramonet, 2004). Los escenarios de movilización política en el Internet venezolano se pueden describir como intensos y polarizados; «es un ciberespacio político dominado tanto por la oposición como por los movimientos pro-chavistas" (Morelis, 2004: 3).

Dentro del centenar de sitios web que articulan el movimiento bolivariano se destacan dos en especial:

- $\quad$ Aporrea.org, es el más visitado y de mayor peso en la divulgación de noticias y opinión sociopolítica y cultural. Se identifica con el proceso de transformación revolucionaria de Venezuela. Tiene una clara visión de izquierda, anti-imperialista, anti-capitalista y su objetivo principal es apoyar la construcción del "socialismo del siglo XXI». El portal está diseñado en formato de agencia de noticias, con informaciones y sucesos de diversos movimientos populares, sindicales, culturales y políticos "comprometidos con la revolución bolivariana». Para ello promueve la formación y cooperación de corresponsales comunitarios y reporteros de calle, columnistas colaboradores, equipos editores y enlaces con los movimientos sociales de izquierda. Este sitio nació en mayo de 2002 como portal web de la Asamblea Popular Revolucionaria «APORE», con el objetivo de contrarrestar la ofensiva opositora al gobierno de Chávez en el internet. Posteriormente, Aporrea.org se incorporó a la Asociación Nacional de Medios Comunitarios, Libres y Alternativos "ANMCLA» y transitó hacia un portal noticioso de la red bolivariana.

$\mathrm{Al}$ igual que los portales indígenas en Ecuador, gran parte de sus recursos financieros provienen de donaciones del gobierno cubano, venezolano y de otros grupos activistas internacionales. También defienden el software libre de Linux y tienen un enlace con el motor de búsqueda de Google. Se patrocinan además con publicidad, práctica no muy reconocida en este tipo de portales, pero que defienden como alternativa para mantener y actualizar la plataforma tecnológica.

- $\quad$ Anti Escuálidos (antiescualidos.com) es quizá el mejor sitio bolivariano y pro-chavista desde el punto de vista tecnológico y documental. Su objetivo principal es ofrecer un seguimiento permanente a la revolución bolivariana en Venezuela, desde las políticas sociales hasta las relaciones internacionales. Mantiene una colección digital de documentos de Simón Bolívar, Marx, Lenin, el Che Guevara y Chávez. Su buscador está integrado a Google y mantienen listas de opinión de izquierda sobre diversos temas.

Más allá de estos sitios anclados en Venezuela, la red bolivariana constituye una diáspora en países tan diversos como Estados Unidos, Francia, Islas Canarias, Argentina, Chile y Bolivia, donde surgen portales nacionales que condensan documentos y boletines a favor de la revolución bolivariana. Son los portales más sencillos y menos sofisticados de los consultados, pero que proliferan con bastante fuerza por la red. Así mismo, el círculo bolivariano se articula a macroespacios como Nodo50, Andalucía Libre, Emancipación.org y Rebelión.org.

GOBIERNOS ELECTRÓNICOSY ACCIÓN COLECTIVA ATRAVÉS DEL INTERNET: DINÁMICAS EN LA REGIÓN ANDINA 


\subsubsection{Los marchistas de Facebook}

La movilización del 4 de febrero de 2008 en las principales ciudades de Colombia y en otras ciudades del mundo, nace y se coordina un mes antes desde el grupo de Facebook «Un millón de voces contra las FARC». Al margen de las consideraciones ideológicas y valorativas que despiertan este tipo de actos, en un país no acostumbrado a estas manifestaciones masivas e inmerso en un complejo conflicto con diversos responsables, esta marcha demostró ser el producto inédito y exitoso de las comunidades virtuales, que aprovechan la tecnología informática en pro de la acción colectiva.

La propuesta logró congregar unas 260.000 personas en la red Facebook (colombianos y otras nacionalidades), quienes se dividieron en comités coordinadores según la ciudad de ubicación de sus promotores. Tal organización de la convocatoria se sustentaba en el uso de potentes herramientas de búsqueda y filtración de perfiles (nacionalidad, estudios, profesión, edad, actividades preferidas, ubicación actual, entre otros), variables que cada usuario de estos portales señala al momento de su registro. Con esto se logra seleccionar miles de usuarios con altas afinidades entre sí (grupo). Luego, el grupo comparte una serie de módulos en línea que permiten importar bases de correo electrónico, gestionar agendas, transferir archivos, vender y comprar mercancías con pago electrónico, publicar artículos y notas (www.facebook.com).

Estos casos revelan una clara tendencia hacia la adaptación y uso del internet por parte de los movimientos sociales en la región. Es un laboratorio interesante, novedoso y en rápida expansión. Sin embargo, debemos detenernos un poco para realizar algunas consideraciones politológicas sobre el alcance y el potencial de la movilización a través de internet.

\section{3. ¿Qué aporta internet a la movilización social y política?}

La contribución del internet a la movilización social y política puede resumirse en dos vías:

- La primera vinculada a los avances técnicos que soportan la autopista de la información. Se percibe una serie de rupturas frente a los medios tradicionales de comunicación (prensa, radio y televisión), derivadas del uso de dispositivos de comunicación en red, protocolos y portales web mundiales que convergen en una transmisión de información cuyo coste y tiempo de acceso no es proporcional a la distancia donde se produce y donde se recibe. Una comunicación en tiempo real, instantánea, además de interactiva; una relación que aunque no es completamente horizontal, contrasta con la comunicación jerarquizada y unilateral de los espacios institucionales que los movimientos sociales desafían (Sádaba, I., 2002). El email, los foros en línea, el chat y los portales con información dinámica y permanente son herramientas técnicas que favorecen las respuestas inmediatas, la difusión mundial y la multiplicación de centros de emisores y receptores activos.

- La segunda, el internet ha cimentado en sí mismo un nuevo escenario de acción colectiva, de participación, de lucha y de resistencia en lo social y político. Al respecto, para Hardt y Negri el régimen del internet puede ser caracterizado como una hibridación o un modelo dual que 
incita a la acción colectiva: uno de mecanismos democráticos, otro de tendencia oligopólica (Hardt y Negri, 2001). El espacio democrático está formado por actores que construyen nuevos espacios y redes de intercambio, enfocados en abrir nuevas formas de participación virtual y extensión de la ciudadanía a lo digital. En la red oligopólica, los actores deben resistir a la producción centralizada y unicultural, a la necesidad de la tarjeta de crédito para abrir hipervínculos, a la distribución en masa de virus y contenidos basura. Ambos espacios configuran movilizaciones novedosas, exclusivas de la arena del internet: la lucha por el software libre (open source), la lucha por el acceso gratuito a la información (open access), la lucha contra las megacorporaciones informáticas (hacktivismo), la huelga y el sabotaje informático (mailbombings), movilizaciones colectivas que presionan a instituciones, corporaciones y opinión pública con un efecto quizá comparable a una movilización campesina.

Cabe anotar que el objeto en este punto no es discutir qué pesa más «una movilización campesina o una página web, una huelga o un virus», sino verificar si la inserción en la red se traduce en un fortalecimiento de los movimientos sociales y de su accionar social y político. En tal sentido, el texto de León, Burch y Tamayo presenta pistas interesantes. Para estos autores, el "capital informacional» o la capacidad de un colectivo para usar las herramientas de internet a favor de su acción social y política, complementaria a los recursos y su capacidad de presión o movilización en el mundo «real», se convierte en una categoría analítica válida y obligatoria para entender el fracaso de unos, la adaptación y consolidación de otros y el surgimiento de nuevos movimientos sociales en la era del internet (León, Burch y Tamayo, 2001: 48-63).

A partir de las experiencias como la de los ciberindígenas y los ciberbolivarianos podemos destacar dos condiciones básicas que permiten la inserción y fortalecimiento de un movimiento social en internet:

- $\quad$ La primera, que el movimiento perfile con claridad las políticas y estrategias de comunicación. Esto implica el tránsito de una lógica de medios (instrumental) a una de objetivos, teniendo un marco más amplio de potenciales militantes, tantos como el internet puede proveer, a los cuales debe cautivar y transmitir las ideas en forma lógica, documentada, creativa, incluso sofisticada (Norris, 2004: 34). En esa dirección, en un estudio reciente sobre movimientos latinoamericanos en la red, Silvia Lago muestra cómo

«A partir del uso de internet se empezó a dar un lugar específico a la comunicación (en la estructura del movimiento) y se formaron áreas o departamentos de comunicación, que significaron la ampliación del equipo de trabajo, del espacio físico, y del equipamiento. Fue necesario dedicar recursos humanos exclusivamente a todo lo relacionado con internet, puesto que era primordial realizar una clasificación de la enorme cantidad de información que llega a través del correo electrónico y, al mismo tiempo, seleccionar los materiales a publicar en la red bajo determinados parámetros y objetiVOS» (Lago, 2006: 12). 
- La segunda condición reside en la construcción de alianzas con otras redes de movimientos globales, incluso con empresas y gobiernos. En efecto, ejemplos como el de los marchistas de Facebook demuestran que la movilización social en el siglo XXI no puede concebirse desde una organización tradicional, parroquiana, localista en sus demandas y sin asociación con otros. Por el contrario, los macroespacios de convergencia abordados en este artículo nos muestran que los movimientos en red son, en esencia, coaliciones y alianzas regionales o continentales que se constituyen en torno a diversos valores y proyectos, y que utilizan todo el arsenal mass-media y multimedia para obtener amplificación y resonancia.

Estas dos condiciones se encuentran presentes en la práctica de los principales movimientos sociales andinos que incursionaron en internet, como lo observamos en la primera parte de la segunda mitad de este artículo. Ahora, deslicemos la lupa a la otra orilla.

\section{4. ¿Qué aportan los movimientos sociales al internet?}

Para autores como Bert Klandermans, la acción de los movimientos sociales ha favorecido el mejor uso del internet y ha despertado una reflexión transformadora sobre el papel que desempeña dicha tecnología en el rumbo de la civilización humana. El argumento del autor se presenta de la siguiente forma: «Los movimientos sociales en red han aportado el marco de justicia, la identidad y el sentido de eficacia que el '.com' había eliminado del internet»(Klandermans y Staggenborg, 2002).

Tal como se duda que la mano invisible del mercado establezca justicia social y por tanto se deban implementar mecanismos de política social y resistencias al capitalismo para custodiarla, así mismo en internet se debe dudar que la justicia provenga de protocolos y aplicaciones compatibles, sin gobierno aparente. Por esto, debe desplegarse resistencias colectivas que interpreten la realidad de la red, denuncien las situaciones que, a la luz de principios ya sea democráticos, morales y/o humanos sean equivocadas y deban ser corregidas. Los delitos cibernéticos, el monopolio informático, el abuso contra el cibernauta, la restricción a la información, entre otros, son escenarios en los que se requiere de la movilización de colectivos para revertir o resistir tal situación. En ello, proyectos como Indymedia y los altermundialistas juegan su papel.

La condición de identidad se torna vital para el desarrollo del internet, ya que hace referencia a la construcción de un sentido de pertenencia para alimentarlo, orientarlo y hacerlo accesible y funcional. Dado los millones de portales web que proliferan y nacen cada día, el internet se vuelve difuso, impersonal, complejo y saturado. En ese punto, la creación de una comunidad virtual unida por intereses y proyectos contribuye a reducir la entropía de la red. La Pachamama que sirve de entrada a los portales indígenas de la CONAIE o los portales presentados en dialectos diversos de la cultura latinoamericana son evidencia de esa necesidad de identidad en el internet.

Generar un sentido de eficacia implica que los individuos y las organizaciones reconozcan la capacidad del internet para lograr los objetivos que persiguen. Es evidente que mercadolibre.com puede 
incrementar las ventas de un negocio, pero ipuede movimientos.org hacer lo mismo en el plano político y social de un colectivo?, ¿pueden obtener resonancia? Al respecto se puede indicar que los movimientos sociales andinos han venido copando cada vez más el ciberespacio, consiguiendo con ello resultados a veces espectaculares e inéditos de apropiación, como las iniciativas de traducción de la web a lenguas nativas indígenas en Perú, Ecuador y Bolivia; o su utilización para canalizar recursos y generar alertas contra el conflicto armado en Colombia.

En síntesis, se trata de un proceso constructor de sujetos políticos, que ejecutan acciones con un impacto amplio en la sociedad y en el ciberespacio.

\section{CONCLUSIONES}

Las nuevas tecnologías de la información plantean para la región andina un doble propósito: preparar al Estado para la era digital y fortalecer la participación colectiva y la movilización social. Esos propósitos son posibles hallarlos gradualmente en los gobiernos electrónicos y en los movimientos sociales andinos, que han decidido encarar el reto y explorar las posibilidades.

La relación actual del Estado y los ciudadanos con la informática es de naturaleza simbiótica y dinámica, lo cual exige replantear los análisis que sobre el gobierno, la administración pública y la acción colectiva se restringen a los espacios de movilización tradicional y a la función exclusivamente instrumental del Internet. Surge un nuevo catálogo de acciones sociopolíticas que se valen de recursos tecnológicos disponibles ante la crisis de organizaciones más tradicionales y estructuradas como partidos políticos, sindicatos, y asociaciones cívicas formales.

Nuevos espacios de convergencia son utilizados, las plataformas web ya sean de Estados o de movimientos sociales se expanden y se articulan con todo el planeta. Este tipo de estructura ha permitido simultáneamente la coordinación de ajustes estructurales y de acciones colectivas al interior de los países andinos y su articulación con otras acciones en diferentes lugares del mundo. Los portales de gobierno electrónico son homogéneos en cuanto diseño y función. Se configuran como la evidencia principal de la adaptación del Estado a una era informática. Su desarrollo frente a la democracia aún es precario, su impacto sobre la modernización y la administración pública es innegable. En cuanto a los movimientos sociales, sus plataformas no son homogéneas en diseño y función. Observamos una centralidad en los portales indígenas y su incorporación como sustrato de la organización. Para la red bolivariana, los portales se descentralizan y son utilizados principalmente como soporte para la difusión y la comunicación en masa. Para los marchistas del Facebook, la herramienta se utiliza como aglutinador masivo de perfiles. En todo caso, en estos procesos se observa la capacidad de articular expresiones políticas y construir sujetos políticos en internet. El valor de las iniciativas nacionales es precisamente ofrecer experiencias y espacios abiertos para la deliberación de los colectivos y preparar el camino para otras organizaciones. Al mismo tiempo, el papel del internet y las nuevas tecnologías va ocupando cada vez más espacio en el debate propio 
de los movimientos y en sus acciones, al punto de encontrar indígenas defendiendo el pingüino de Linux frente a Microsoft, y a colectivos anti-imperialistas compartiendo con Google. En consecuencia, el internet imprime un nuevo capítulo en las trayectorias de los movimientos sociales a la vez que estos abren nuevos horizontes que podrán incidir en la evolución de los gobiernos electrónicos y la consolidación democrática en la región.

\section{BIBLIOGRAFÍA}

Bellamy, Ch. y Taylor, J.A. 1998. Coverning in the Information Age, Buckingham, Open University Press.

Bellamy, C. 2004. «Modelling electronic democracy: towards democratic discourses for the information age», en Hoff, Horrocks \& Tops (eds), Democratic Governance and New Techonology, Routledge.

BID. 1998. «El desafío informático del 2000», en BIDAmérica, noviembre/diciembre.

Castells, M. 2001. La galaxia internet. Reflexiones sobre internet, empresa y sociedad. Barcelona, Plaza \& Janés.

. 1997. La era de la información. Economía, sociedad y cultura. Madrid, Alianza Editorial.

Comisión Europea. 2002. Informe de evaluación comparativa de la acción e-Europe, 62 final, Bruselas: Dirección para la Sociedad de la Información.

. 2001. Libro Blanco sobre la Gobernanza Europea. Bruselas: COM (2001) 428 final. http://europa.eu.int/ comm/governance/index_en.htm

. 1999: 'e-Europe: una sociedad de la Información para todos', http://europa.eu.int/comm/ information_society/index_es.htm

. 1997. La construcción de la sociedad europea de la linformación para todos nosotros.

Criado, J.I. \& Ramilo, M.C. 2001a. «e-Administración: ¿un reto o una nueva moda para las administraciones del siglo XXI? Algunos problemas y perspectivas de futuro en torno a internet y las tecnologías de la información y la comunicación en las administraciones públicas». En Revista Vasca de Administración Pública, 61 (I), pp. 11-43.

. 2001b. «Definiendo la e-Administración. Las Páginas Web de las Administraciones Públicas». En Gestión y Análisis de Políticas Públicas, 22, en prensa.

2001c. «QQué está Haciendo hoy Internet en el Ámbito Local? Análisis Comparado de las Comunidades Autónomas del País Vasco y Madrid», en Inguruak, Revista Vasca de Ciencias Políticas y Sociología, 30, en prensa.

Díaz Batista, E. 2004. «Ciberong o uso da internet por ongs no brasil, são paulo: rede de informações para o terceiro setor», disponible en http://www.rits.org.br/rets/download/centro_estudos_150405.zip .

Fleischman, L. 2004. Internet y movimientos sociales: comunicación en los movimientos de resistencia global, IAMCR conference.

Carlos Germán Sandoval 
Grimshaw, D. 2003. «Responding to New Technologies». Conceptual Framework. Intermediate Technology Development Group (ITDG).

Hardt, M. y Negri, A. 2001. Império, Río de janeiro, record, p. 319.

Hood, Ch. 1998. The Art of the State. Oxford, Oxford University Press.

. 1997. «Racionalismo Económico en la Gestión Pública: ¿De la Administración Pública Progresiva a la Nueva Gestión Pública?». En Brugué, Quim y Subirats, Joan (Comps.), Lecturas de Cestión Pública, Madrid, MAP, pp. 469-490.

. 1991. «A Public Management for all Seasons? ». Public Administration, 69, 2, pp. 3-19.

Hughes, O.E. 2001. «The Way Ahead for New Public Management». Working paper 55/01, agosto, Department of Management, Monash University, Melbourne.

. 1998. Public Management and Administration, Londres, MacMillan.

Jordana, J. 2000. «nstituciones y capital social ¿qué explica qué?», Revista Española de Ciencia Política, vol. 1, 2, Abril, pp. 187-210.

pp.17-28.

. 1999. «Las Administraciones Públicas y la promoción de la Sociedad de la Información», GAPP, 16,

. 1995. «El análisis de los policy networks: ¿una nueva perspectiva sobre la relación entre políticas públicas y Estado? », GAPP, 3, pp. 77-89.

Klandermans, B. y Staggenborg, S. 2002. Methods of social movement research, Minnesota.

Katz, J. 1999. Reformas estructurales y comportamiento tecnológico: reflexiones en torno a las fuentes y naturaleza del cambio tecnológico en América Latina en los años noventa, Cepal.

Lago, S. y Marotias, A. 2006. «Los movimientos sociales en la era de internet», en Revista razón y palabra, № 54, www.razonypalabra.org.mx

Lago, S. 2004. «Los movimientos sociales altermundialización y el activismo en internet», en www.nodo50.org. Latin American and Caribbean Social Movements and the Internet. 2004. Phase II, ww.alai.org

Latin American Newsletters. 2000. Informes especiales: el internet en América Latina. Evaluando su éxito, Londres.

León, O.; Burch, R. y Tamayo, E. 2001. Movimientos sociales en la red. Agencia Latinoamericana de Información, Ecuador, disponible en http://alainet.org/publica/msred/

Mälkiä, M., Anttiroiko, A., y otros. 2004. Etransformation in Governance. New Directions in Government and Politics, London, Idea Group Publishing.

Mena, E. 2002. «Software libre en América Latina y El Caribe», en Chasquinet, 2002.

GOBIERNOS ELECTRÓNICOSYACCIÓN COLECTIVA ATRAVÉS DELINTERNET: DINÁMICAS EN LA REGIÓN ANDINA 
Morelis, G. 2004. «Ciberpolítica en acción o cómo los venezolanos nos apropiamos socialmente de la red«, en Revista Textos de la cibersociedad, $\mathrm{N}^{\circ} 3$, disponible en http://www.cibersociedad.net

Norris, P. 2004. Building knowledge societies: the renewal of democratic practices in knowledge societies, Cambridge, Harvard University, disponible en http://ksghome.harvard.edu/ pnorris/acrobat/ unesco $\% 20$ report $\% 20$ knowledge $\% 20$ societies.pdf

Olías de Lima, B. (Coord.). 2001. La nueva gestión pública. Madrid, Prentice Hall.

Prieto Martín, P. 2006. «Sistemas avanzados para la participación electrónica municipal: ejes conceptuales para su diseño», en Textos de la cibersociedad, $\mathrm{N}^{\circ}$ 9, disponible en http://www.cibersociedad.net

Raczynski, D. 2000. «Overcoming Poverty in Chile». Social Development in Latin America: The Politics of Reform, Joseph Tulchin and Allison Garland (eds.). Boulder, CO: Lynne Reinner.

Ramonet, I. 2004. «Información y democracia en la era de la globalización», en Revista Ágora, 10, Centro de estudios políticos y sociales.

Sádaba, I. 2002. «Panorama alternativo en Internet», en www.rebelion.org/cibercensura/igro271002.htm.

Sassen, S. 2007. Una sociología de la globalización, Buenos Aires, Katz Editores.

Trechsel, A. 2003. Evaluation of the use of new technologies in order to facilitate democracy in Europe. Edemocratizing the parliaments and parties of Europe, Geneve \& Florence, University of Geneve \& European University Institute, disponible en http://c2d.unige.ch/int/overviewinstits/main_report_final\%201.pdf

UIT. 2005. Programa de combate a la exclusión digital de la Organización de Naciones Unidas, Nueva York. 